\title{
Challenges Facing the Management of Electrical and Electronic Waste in Kenya: The Case Nairobi County
}

\author{
Catherine Wanza Mutua* \\ University of Eldoret, MUSCO Towers, Off Elgeyo Rd, Eldoret, Kenya
}

DOI: $10.36348 /$ jaep.2019.v03i11.001

| Received: 20.06.2019 | Accepted: 27.06.2019 | Published: 12.11.2019

*Corresponding author: Catherine Wanza Mutua

\section{Abstract}

The aim of this research paper is to know the challenges faced by formal and informal sectors in disposing e-waste in Nairobi County. It also tried to identify the e-waste management strategies applied by formal and informal sectors in the county. A total of 400 personals were selected; 250 from informal sector, 150 from formal sectors. Simple random method was used to select the participants included in the sample and stratified sampling method was used to select the sectors involved in e-waste management from which the sample was selected. Questionnaires, environmental observation checklist and Interview guide were designed to ask members of the two sectors, the management strategies they apply and the challenges they face in managing e-waste. It was found that most of the e-waste was not disposed; instead it was stored in warehouses and the percentage disposed it was mainly poorly disposed. Factors which contributed to poor disposal and accumulation of e-waste in warehouses included: Lack of procedures of disposing specific e-waste and lack of information on where to take the WEEE. Different challenges affecting e-waste management strategies were also realized and included: Financial constraints, Disease, Lack of handling procedures, limited number of official dumpsites, access and infrastructure and lack of environmental awareness.

Keywords: E-Waste, e-waste management strategies, e-waste management challenges.

Copyright @ 2019: This is an open-access article distributed under the terms of the Creative Commons Attribution license which permits unrestricted use, distribution, and reproduction in any medium for non-commercial use (NonCommercial, or CC-BY-NC) provided the original author and sources are credited.

\section{INTRODUCTION}

E-waste is a generic term comprising all electrical and electronic equipment (EEE) that have been disposed of by their original users. This includes everything from large household appliances, such as refrigerators, microwaves, ovens, television sets, computers, hand-held digital devices, cell phones and toys [1] Several environmental protection agencies around the world consider e-waste to be hazardous waste because they have chemicals compounds in their composition that are toxic and harmful to human health and to the environment.

The Nairobi County has the highest number of industries in one locality in the country and in East Africa at large, most of which are manufacturing and processing. Currently the sector is one of the largest in sub Saharan Africa. Industrialization is also expected to grow to higher levels, and provisions in the vision 2030 and the Constitution of Kenya 2010 that embraces county governments and economic growth in general have necessitated this. The presence of these will lead to a rise in e-waste from passive elements due to increased changes in technology, wear and tear, and high rates of obsolescence of the electrical and electronics equipment's and modules in the industries [2].

The purpose of this study was to determine challenges facing formal and informal sectors dealing with Electrical and Electronic waste management in Nairobi County. The study was conducted in Nairobi County and dealt with the challenges related to: the nature, amount of e-waste and e-waste mechanisms applied by the two sectors. The study covered e-waste from Televisions, computers, mobile phones, fridges, radios and microwaves.

\section{METHODOLOGY}

The study employed both qualitative and quantitative research. This allowed data collection and analysis to be carried out the same time. That is, as the data was collected, analysis of the same data was going on. This gave the researcher to establish categories and themes of the inquiry as they emerged from the data. Hence the researcher was able to consider both formal and informal sectors in e-waste management and at the same time was able to identify the challenges hindering 
Catherine Wanza Mutua; J Adv Educ Philos, Nov 2019; 3(11): 384-387

the adoption of effective e-waste management strategies.

Qualitative method was considered particularly suitable for gaining an in-depth understanding of underlying reasons and motivations in e-waste disposal while quantitative method which involves measuring or counting attributes was used as a systematic approach to investigate numerical data collected and the researcher transformed what was collected or observed into numerical data. Statistical techniques such as tables, pie charts and Bar charts were used to analyze and present the collected data.

In this study, research ethics was taken care of by making sure that the study was explained to large groups of participants and only those who were volunteered were interviewed. Also the researcher made clear to the volunteers that they had right to refuse to answer any questions if they were not comfortable with and even to withdraw from the study at any point if they felt uncomfortable in the direction it took. Confidentiality which protects the participants against risks of embarrassment, job related risks and any other risks harmful to the participants were ensured. This was achieved by ensuring the real names of participants were not used in the data or in the text and was not available to anyone except the researcher.

The total combined sample size of the study was 400 , comprising of 250 workers from informal sector, 150 workers from formal sector. This sample was adequate for the study since Neumann [3] argue that we cannot study every case whatever we are interested in, or should we want to. The sample size depends on what one wants to know, the purpose of the inquiry, what is at stake, what will be useful, what will have credibility and what can be done with available time and resource [4].

For this study, sample size depended on the purpose of the inquiry, what was at state, what was useful, what was bringing credibility and what was to be done with the available time and resources. The study adopted simple random sampling and stratified sampling techniques. Simple random sampling technique was used to select participants from the two organizations selected. This ensured that each organization and each worker selected was given an equal chance of being selected and included in the study.

The study was conducted using questionnaires, interviews and observation. The instruments had questions related to the research questions. Mugenda \& Mugenda [5] argue that an interview is an oral administration of a questionnaire or an interview schedule is a face to face encounter between a researcher and a respondent. Questionnaires were used so as to give the respondents adequate time to provide well thought out responses in the questionnaires items.

The choice of the instrument was also because of the sample size as Saunder [6] argue that questionnaire method provides an efficient way of collecting responses from a large sample. Each item in the questionnaire was developed to address a specific objective of the study or research question. Therefore rules of constructing questionnaires and questionnaire items as well as ordering of items of in questionnaires were keenly observed to ensure standard questionnaire which can be interpreted the same way by the respondents. Questionnaires work best with standardized questions that you can be confident will be interpreted the same way by all respondents [7].

Research permit was sought from the National Commission for Science, Technology and Innovation (NACOSTI) before embarking on field study. This was done in courtesy of the Department of Technology Education, School of Education at University of Eldoret. Therefore a clearance from County Government of Nairobi was sought. The CEOs of the organizations sampled were given copies of research permit on day of visit.

To refer to the different institutions, the study used subscribes A, B, C, D and E in place of their names. An interview was conducted to three institutions each from the three categories of institutions as reflected by table 3.An interview method was preferred as it provides greater opportunity to explain the purpose of the study. The use of interviews can help one to gather valid and reliable data which is relevant to the research questions and objectives [6]. This fact is significant since the nature of the interview carried out in this study was consistent with research questions, objectives and purpose of the study. All interviews conducted from participants were audio taped to ensure the exercise was conducted quickly.

At the beginning of each group meeting for interview and questioner issuance, introduction for the researcher was done. Then the following orientating statement was read to the participants." As we begin this meeting I would like to give you some information about the project and explain to you why the project is so important. This study will develop my experience as a university student and later as a tutor at Masai Technical Training Institute. In these two cases I found that there is a lot of miss use of e-waste and poor disposal of these waste materials which cause environmental pollution. As an educator I found this situation quite disturbing so much that when I got a chance for doing a research project I choose to address this problem.

From the information we generate in the study you and I will make it available and make us and others 
understand the reason why we need to know the challenges which affect e-waste management strategies adopted by both formal and informal sectors. Such information will be quite useful to everybody as we all need clean environment for survival. At this stage I am asking those of you who are for this study to reflect at this subject and provide necessary information. The information that will be obtained at any stage will be used for this project only. No names or any form of identification of who supplied which information will be given to anyone else. Pseudonyms will be used whenever questions are used anywhere in the project. Thank you." After the introductory statement was given the participants were given a chance to ask questions. Then, the participants were requested to volunteer themselves and they were selected on the first come first served biases. In this study the participants are referred by pseudonyms in place of their real names. The researcher is referred to as C.W.

Validity is the extent to which the instrument measures what it is supposed to measure according to the researchers subjective assessment [8]. Validity deals with the adequacy of the instruments. To ensure validity of the instruments, the designed questionnaires were given to the two academic advisors in the Department of Technology Education to determine their validity. The instruments ware then amended according to the experts commends and recommendations before being administered, to ensure content validity.

\section{RESULTS AND DISCUSSION}

When responses were asked about the disposal mechanisms applied in e-waste disposal, 68(34.293\%) uses burning, 37(18.586\%) burying, Recycling 90(45\%) and unspecified methods 5 (2.5\%).The unspecified methods were procedures for extracting only the valuable part of WEEE and included use of more than one method. To compare the usage of different disposal mechanisms as applied by the formal and informal sectors the following data was presented .For the formal sector; burning was $28 \%$, burying $20 \%$, recycling $45 \%$ and other unspecified methods $7 \%$. For the informal sector; burning was $32 \%$, burying $5 \%$, recycling $28 \%$ and others $38 \%$. Figure- 1 shows comparison between formal and informal disposal mechanisms.

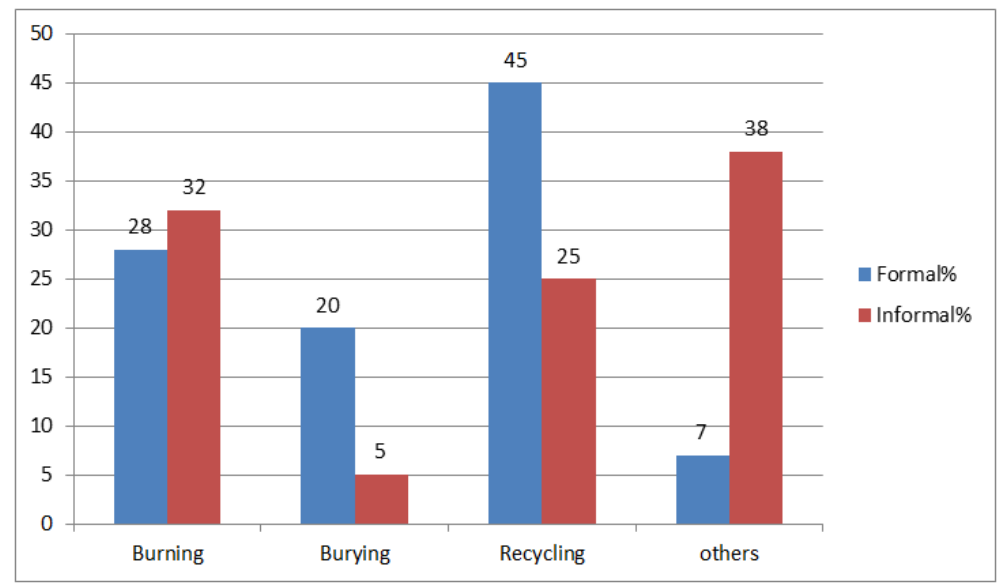

Fig-1: Disposal mechanisms in formal and informal sectors.

All responses 200(100\%) agreed that there were challenges related to the disposal mechanisms applied in disposing e-waste. The following are some of the challenges.

\section{Finance Constrains}

This was the main challenge mentioned by most of the responses $(199,99.5 \%)$.For the formal sector, this challenge hindered disposal of much ewaste hence the percentage of e-waste disposed was low about $(25 \%)$. For the informal sector, finance constrains lead to the use of unspecified methods and lack of protection garments like gloves, face masks, boots and overalls.

\section{Lack of procedures for handling e-waste}

This was also another main challenge for the informal sector. $100 \%$ of the responses from informal sector outlined that they had no procedures for handling e-waste and this had affected their health since they wound handle hazardous e-waste without following the right procedures. This was not a challenge for the formal sector since they had the procedures.

\section{Lack of training in handling e-waste}

$20 \%$ of the responses from informal sector outlined that they were not aware of the hazardous components and how to deal with them while extraction the valuable components. Hence they needed training on the same. For the formal sector most of them had the training but lacked the necessary experience.

From analysis, both formal and informal sectors use same disposal mechanisms but the extent is quite different. From the figure 1 it is clear that in formal sector recycling is their main disposal mechanisms as compared to informal where undefined methods which have health risks are applied. Also in 
formal sector, burying is more applied than in the informal sector where space for burying is not available.

The challenges are more felt by the informal sectors than the formal sectors. Lack of procedures of disposing and training on the right procedure to dispose a specific e-waste were main challenges in the informal sectors. The main challenge for the formal sector was financial constrains which was also a challenge in the informal sector. This was because the provision from government was not enough to train as well as to dispose increasing amounts of e-waste.

\section{CONCLUSION AND RECOMMENDATION}

- In general most informal industries have not put in place measures to address the problem of e-waste management and general environmental health and safety guidelines; this includes corporate policies on e-waste, ewaste handling procedures, and environmental health and safety measures.

- The formal sectors dispose low percentage of e-waste due to financial constrains. .

- Education, training and awareness creation on e-waste menace by the county government and NEMA to the formal and informal sectors and other stakeholders.

- Creation of environmental awareness by mainstreaming e-waste related issues into media coverage and production of environmental publication.

- County government of Nairobi should put in place county monitoring and evaluation structures in order to monitor and evaluate ewaste management projects

- A future study should look at the issue of technology transfer, training and e-waste education in detail, covering both formal and informal sectors and provide comprehensive model of training programmes designed after intensive discussions with relevant stakeholders including universities and professional associations.

\section{REFERENCES}

1. Anyango, J. T. (2011). E-waste Management in Kenya: The Case of ICT, University of Nairobi.

2. Muhani, D. A. (2012). A Framework for Sustainable E-Waste Management in Manufacturing and Processing Industries, Industrial Area Nairobi County, Kenya (Doctoral dissertation, Kenyatta University).

3. Neumann, R., \& Strack, F. (2000). "Mood contagion": the automatic transfer of mood between persons. Journal of personality and social psychology, 79(2), 211.

4. Patton, M. Q. (2002). Two decades of developments in qualitative inquiry: A personal, experiential perspective. Qualitative social work, 1(3), 261-283.

5. Mugenda, O., \& Mugenda, A. (2003) Research Methods, Quantitative and Qualitatively Aproache, Act Press, Kenya.

6. Saunders, P. (2003). Social theory and the urban question. Routledge.

7. Robson, P. (2002). The economics of international integration. Routledge.

8. Frankfort-Nachmias, C., \& Nachmias, D. (2007). Study guide for research methods in the social sciences. Macmillan. 